\title{
Studi komparasi traffic island Ciung Wanara di Gianyar dengan traffic island Satrya Gatotkaca di Tuban
}

\author{
I Komang Priyanata ${ }^{1}$, Cokorda Gede Alit Semarajaya ${ }^{1 *}$, Ni Wayan Febriana Utami² \\ 1.Prodi Arsitektur Pertamanan, Fakultas Pertanian Universitas Udayana, Indonesia 80232 \\ *E-mail: coksemarajaya@unud.ac.id
}

\begin{abstract}
Comparative study of Ciung Wanara traffic island in Gianyar with Satrya Gatotkaca traffic island In Tuban. Traffic island is an island in the middle of the road that serves to direct the flow of traffic and a waiting place for the user to cross the road. Traffic island of Ciung Wanara in Gianyar and Traffic island of Satrya Gatotkaca in Tuban had turned their function of being a place of recreation for the community. The purpose of this study is to invent existing condition of Ciung Wanara and Satrya Gatotkaca traffic island. This study also provides recommendations in the form of designs that can improve the function of the site. The method used in this research was field survey by conducting observation, distributing questioner and doing interview. Research showed that, users in Ciung Wanara traffic island were dominated by student while users who came to the traffic island Satrya Gatotkaca were dominated by employees. The selection of vegetation bettwen the traffic island of Ciung Wanara and traffic island of Satrya Gatotkaca very different. Vegetation in the traffic island of Ciung Wanara used more of large size vegetation that can block the view of the user of the vehicle, while the vegetation used in the traffic island of Satrya Gatotkaca use lower plants size. The recommendation given in both locations was to add access to traffic island of Ciung Wanara so as to make easier for users to find the right place to cross, while traffic island of Satrya Gatotkaca was arraged it crossing space for more convenient and secure for users to passed the crosswalk.
\end{abstract}

Keywords: comparative study, park design, traffic island

\section{Pendahuluan}

Traffic island adalah salah satu jenis ruang terbuka berupa taman yang merupakan bagian dari persimpangan jalan, dibangun sebagai pengarah arus lalulintas serta merupakan tempat tunggu untuk pejalan kaki pada saat menunggu kesempatan menyeberang. Direktur Jenderal Binamarga (2012) menyebutkan traffic island biasanya hanya digunakan oleh pejalan kaki yang hendak menyeberang jalan, ruang pada traffic island dapat dimanfaatkan untuk penempatan fasilitas jalan seperti rambu-rambu lalulintas dan tiang lampu penerangan. Kabupaten Gianyar memiliki traffic island yang menjadi ikon kabupaten Gianyar yang terletak disebelah barat kantor bupati yaitu traffic island Ciung Wanara. Lokasi traffic island berikutnya terletak di desa adat Kelan, kelurahan Tuban, Kecamatan Kuta, Badung. Terletak disebelah utara Bandara Ngurah Rai Bali dan menjadi ikon Kelurahan Tuban yaitu traffic island Satrya Gatotkaca. Kedua tempat ini dipilih sebagai lokasi penelitian karena kedua tempat ini merupakan traffic island dan kedua tempat ini dapat dimanfaatkan oleh masyarakat sebagai tempat berekreasi.

Berdasarkan latar belakang di atas maka perlu dilakukan penelitian terhadap Studi Komparasi traffic island Ciung Wanara di Gianyar dengan traffic Island Satrya Gatotkaca di Tuban. Hasil dari penelitian dapat menunjukan lokasi mana yang masih berfungsi sebagai traffic island dan lokasi mana yang sudah berubah fungsinya. Sehingga dapat merekomendasikan rencana ruang di kedua lokasi tersebut agar dapat menjadi acuan pengelola untuk mengembalikan fungsi utama tapak sebagai traffic island.

\section{Metode Penelitian}

2.1 Waktu dan Tempat Penelitian

Penelitian dilakukan di area traffic island Ciung Wanara di Kabupaten Gianyar dan di traffic island Satrya Gatotkaca di Tuban Kabupaten Badung. Kegiatan penelitian dilaksanakan selama 13 bulan yaitu dari bulan November 2016 - Desember 2017. Dapat dilihat pada gambar 1. 


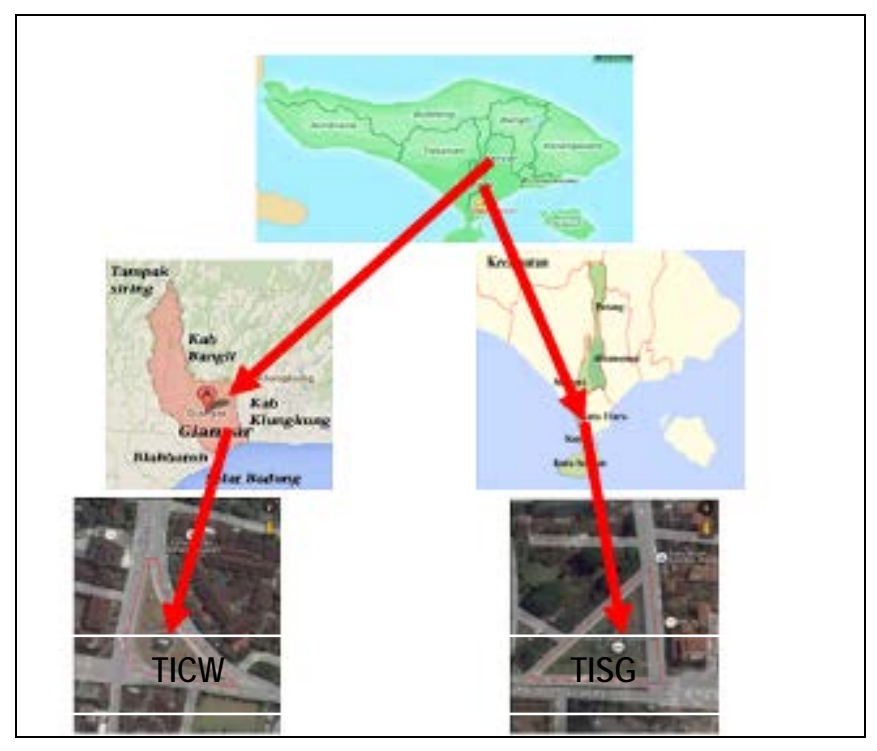

Gambar 1. Lokasi Penelitian

\subsection{Alat Dan Bahan}

Bahan dan alat yang digunakan untuk pengumpulan data dalam penelitian ini adalah peta dari Google Earth, lembar kuesioner, kamera digital dan komputer dengan perangkat lunak AutoCAD

\subsection{Pengumpulan Data}

Jenis data yang digunakan dalam penelitian ini adalah data primer dan data sekunder. Data primer merupakan data yang di peroleh secara langsung oleh peneliti dari sumbernya melalui pengamatan langsung di lapangan (observasi). Peneliti juga menggunakan kuesioner yang disebarkan kepada pengguna tapak yaitu kuesioner terbuka. Kuesioner terbuka menanyakan tentang area mana yang paling sering dikunjungi, apa alasan memilih area tersebut, aktifitas apa yang bisa dilakukan dan bagaimana perasaan pengguna saat berada pada area tersebut. Wawancara dilakukan kepada pengelola traffic island Ciung Wanara di Gianyar dan pengelola traffic island Satrya Gatotkaca di Tuban yang bertujuan untuk mengetahui informasi terkait objek penelitian.

\subsection{Analisis dan Sintesis}

Untuk menghitung hasil kuesioner dalam penelitian ini dilakukannya tabulasi data dalam bentuk persentase (\%). Menurut Sudjana (2001) Teknik tabulasi data ini digunakan untuk menghitung jumlah pilihan responden (f) dibandingkan dengan jumlah keseluruhan responden $(\mathrm{N})$ ke dalam bentuk persentase (\%). Perhitungan persentase ini menggunakan rumus yaitu:

$$
P=f / N \times 100 \%
$$

$$
\text { Keterangan: } \begin{aligned}
P & =\text { Persentase } \\
f & =\text { frekuensi } \\
& N=\Sigma \text { total responden }
\end{aligned}
$$

Setelah dilakukan analisis terhadap data hasil observasi, kuesioner dan wawancara, selanjutnya akan dilakukan tahap sintesis yaitu tahapan pemecahan masalah dari taman Ciung Wanara dan taman Satrya Gatotkaca.

\subsection{Batasan Studi}

Lokasi penelitian hanya dibatasi pada area traffic island Ciung Wanara, Gianyar dan area traffic island Satrya Gatotkaca, Tuban. Studi penelitian dibatasi dengan melihat kondisi eksisting dan mengkomparasi kedua lokasi tersebut sehingga dapat memberikan rekomendasi pengaturan ruang untuk dapat meningkatkan fungsi tapak 


\section{Hasil Dan Pembahasan}

\subsection{Gambaran Umum Lokasi Penelitian}

Kabupaten Gianyar memiliki traffic island yang terletak di kelurahan Candi baru kecamatan Gianyar yaitu traffic island Ciung Wanara (TICW). Luasnya sekitar $500 \mathrm{~m}^{2}$. Area ini juga sering digunakan oleh anakanak untuk bermain dan pada setiap hari minggu pagi rutin diselengarakannya Car Free Day. Pemerintah Kabupaten Gianyar telah memperindah tempat ini. TICW Pada malam hari terdapat 350 lampu warna-warni yang akan menghiasi taman ini. Desai eksisting TICW dapat dilihat pada gambar 2.

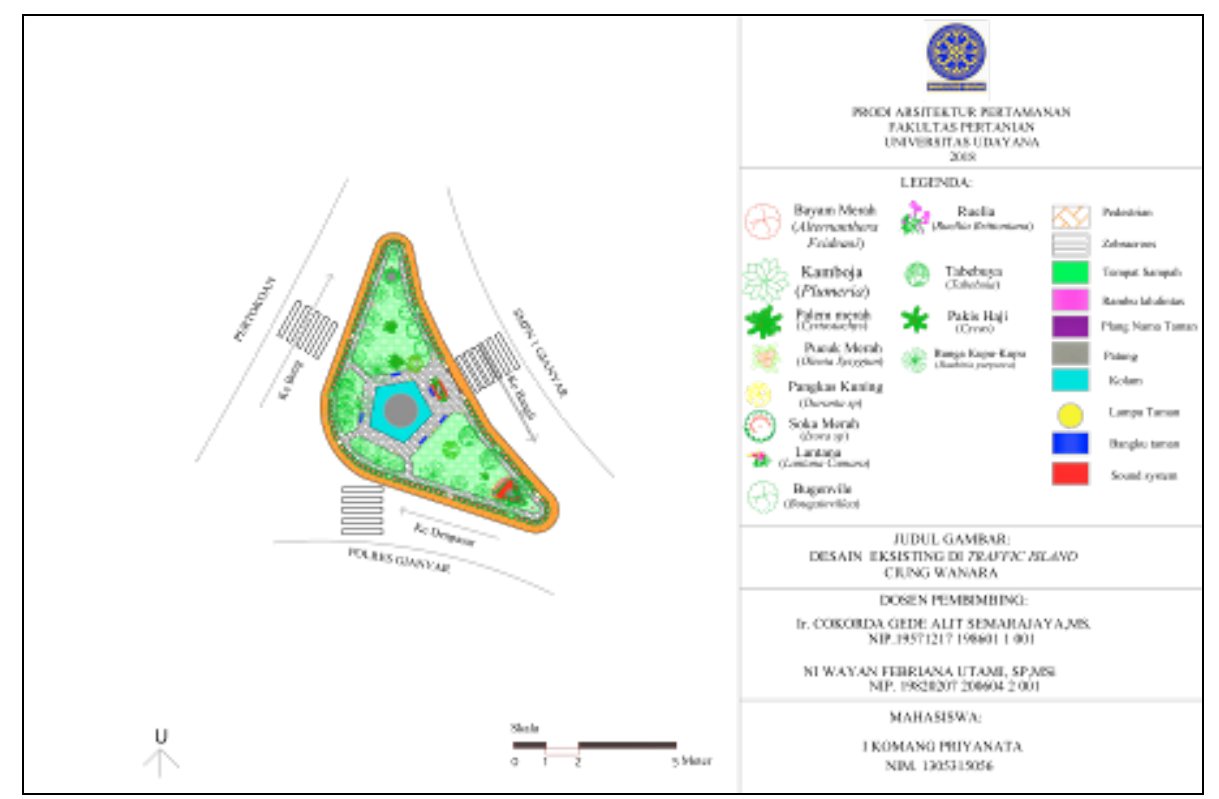

Gambar 2. Desain Eksisting Traffic Island Ciung Wanara

Lokasi berikutnya terletak di desa adat Kelan, kelurahan Tuban, Kecamatan Kuta, Badung. Terletak disebelah utara Bandara Ngurah Rai Bali, yang menjadi ikon Kelurahan Tuban yaitu traffic island Satrya Gatotkaca (TISG) yang terletak didepan Banjar Tuban Griya dengan luas sekitar $370 \mathrm{~m}^{2}$. Patung Satrya Gatotkaca ini didirikan dalam rangka usaha terus memperindah kawasan sekitar Bandara. Desai eksisting TISG dapat dilihat pada gambar 3 .

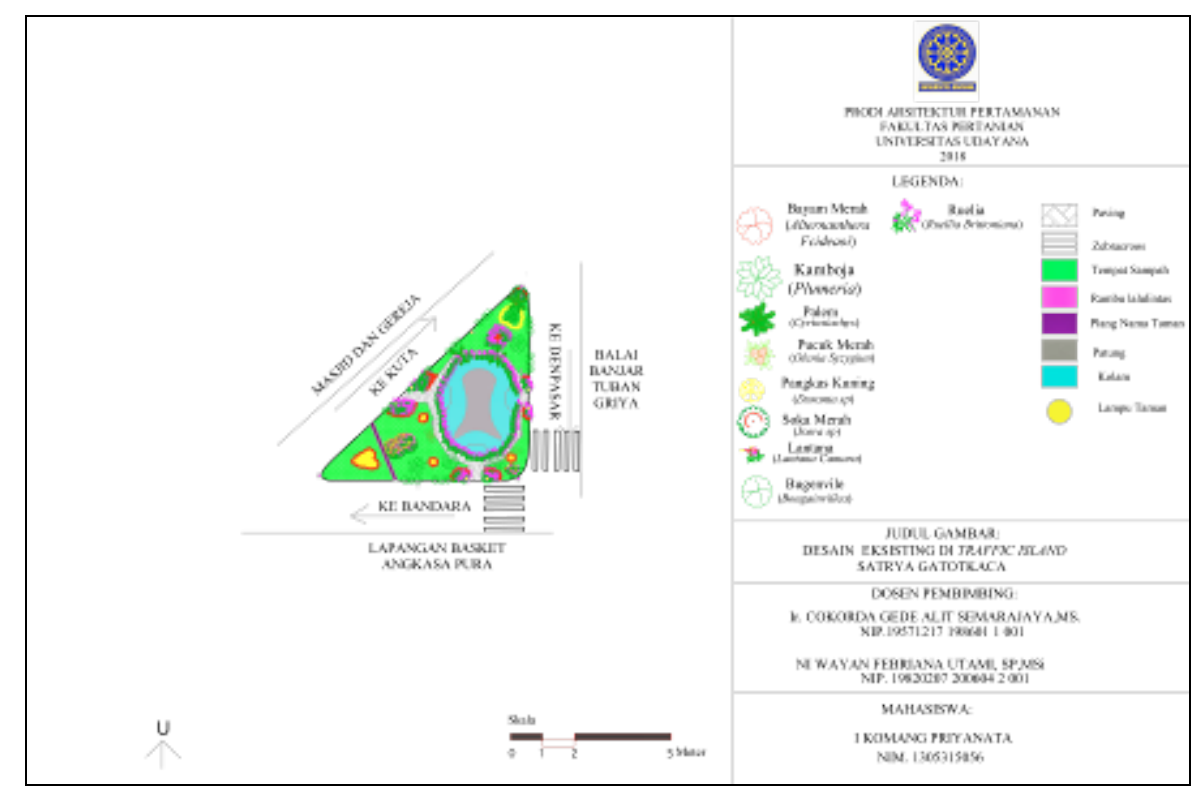

Gambar 3. Desain Eksisting Traffic Island Satrya Gatotkaca 


\subsection{Kondisi Biofisik Traffic Island Ciung Wanara (TICW)}

Kondisi fisik yang terdapat pada TICW yang terletak di Gianyar sangat baik, mulai dari kondisi hardscape seperti patung-patung yang terdapat dalam TICW sangat terawat. Keadaan patung yang berdiri kokoh, indah, bersih, dan berwarna cerah membuktikan bahwa patung tersebut sangat terawat oleh pengelola. Tidak hanya patung elemen hardscape lainya seperti lampu, bangku taman, tempat sampah, jalan setapak dan pedestrian yang berada didalam dan diluar TICW juga sangat terawat.

Kondisi softscape yang terdapat pada TICW yang berupa vegetasi yang ada didalamnya kondisinya juga sangat baik, hasil wawancara dengan kepala bidang pertamanan Kabupaten Gianyar juga mengungkapkan bahwa perawatan softscape pada TICW dilakukan secara rutin oleh satu orang mandor dan tiga orang pekerja.

\subsection{Kondisi Biofisik Traffic Island Satrya Gatotkaca (TISG)}

Kondisi fisik TISG yang terletak di kecamatan Tuban Kabupaten Badung cukup baik, hal ini dapat dilihat dari masih kokohnya patung yang terdapat didalamnya dan kebersihannyapun terus dijaga oleh pengelola. Elemen hardscape lainnya yang terdapat pada taman TISG seperti lampu penerangan, tempat sampah, pedestrian dan jalan setapak keadaannya juga masih bagus, namun penulis menemukan ada beberapa lampu yag rusak dan dibiarkan begitu saja.

Kondisi softscape yang terdapat didalam TISG sangat baik, karena tanaman-tanaman yang terdapat didalamnya dirawat secara rutin. Pengairan sangat penting dalam perawatan tanaman, pada dasarnya semua tanaman membutuhkan air. Pemangkasan juga diperlukan sehingga beban tanaman tidak terlalu berat. Pemupukan dan pengendalian hama juga sangat penting dalam mengelola taman (Wulandari, 2016). Kadar air yang diperlukan tanaman berbeda, idealnya dalam penyiraman tanaman yang terdapat di taman TISG disiram dua kali sehari yaitu pagi dan sore. Pemangkasan juga perlu dilakukan jika tumbuhnya sudah melebihi area yang tersedia dan ukuran yang diinginkan. Pemupukan dilakukan secara rutin selama sebulan dua kali agar tanaman mendapat nutrisi yang cukup.

\subsection{Preferensi Pengguna terhadap Ruang di Traffic island Ciung Wanara}

Prefesensi pengguna di TICW ditentukan dengan membagi lokasi TICW menjadi 4 bagian, dapat dilihat pada gambar 4.

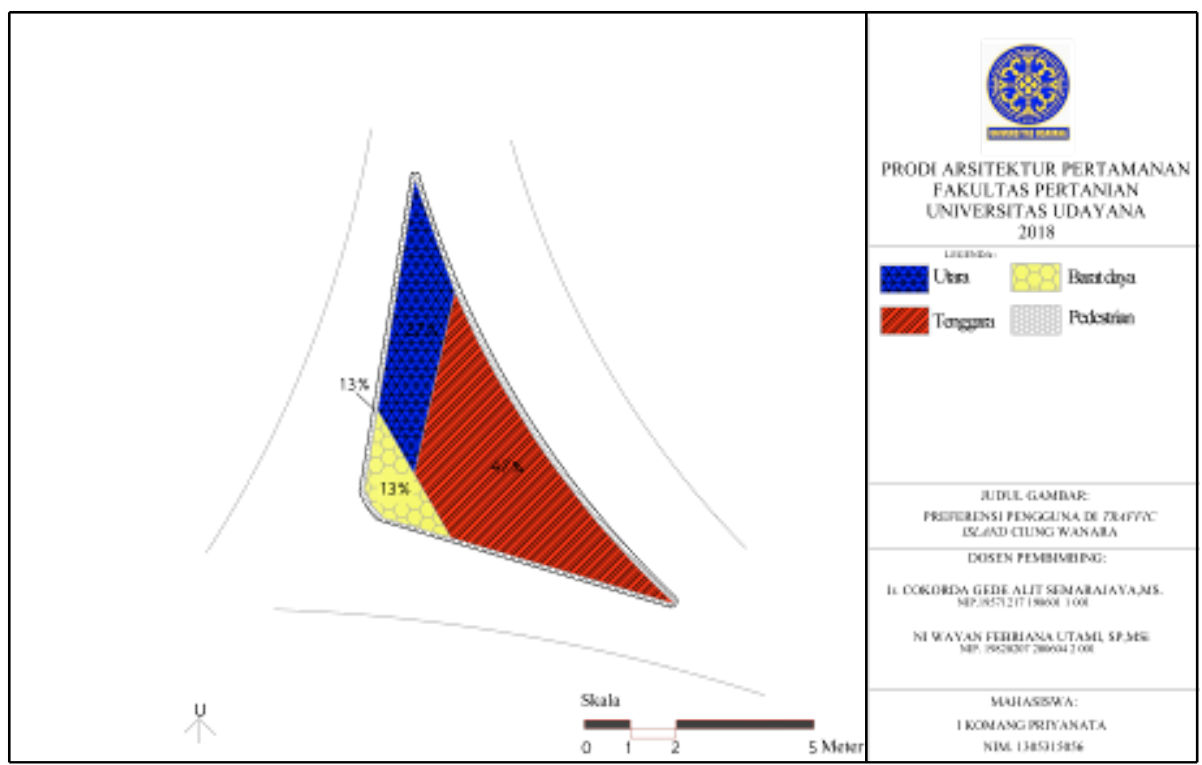

Gambar 4. Blok Plan Preferensi Pengguna di Traffic Island Ciung Wanara

Bagian luar taman yang berwarna puth merupakan pedestrian, sebanyak 13\% pengguna berpendapat sering memakai tempat tersebut untuk menyeberang dengan perasaan yang kurang nyaman karena tidak adanya tanaman peneduh. Bagian yang berwarna biru merupakan bagian utara dari TICW, lokasi tersebut cukup jauh dengan pintu masuk sehingga hanya $27 \%$ pengguna trafiic island berkunjung ketempat tersebut. 
Bagian yang berwarna merah yaitu pada bagian tenggara TICW, 47\% pengguna memilih tempat tersebut dengan alasan lokasi yang cukup luas, dapat melihat keindahan patung, nyaman dan dekat dengan pintu masuk. Bagian taman yang berwarna kuning yaitu pada bagian barat daya taman, hanya sebanyak $13 \%$ pengguna yang memilih tempat tersebut karena lokasi tersebut berada belakang patung utama sehingga pengguna tidak mendapatkan view yang bagus untuk berfoto dan lokasi tersebut juga cukup jauh dari pintu masuk.

\subsection{Preferensi Pengguna terhadap Ruang di Traffic island Satrya Gatotkaca}

Prefesensi pengguna terhadap ruang di TISG ditentukan dengan membagi ruang menjadi 3 bagian, tidak seperti di TICW yang dibagi menjadi 4 bagian, karena TISG tidak terdapat pedestrian pada bagian pinggir TISG. Dapat dilihat pada gambar 5.

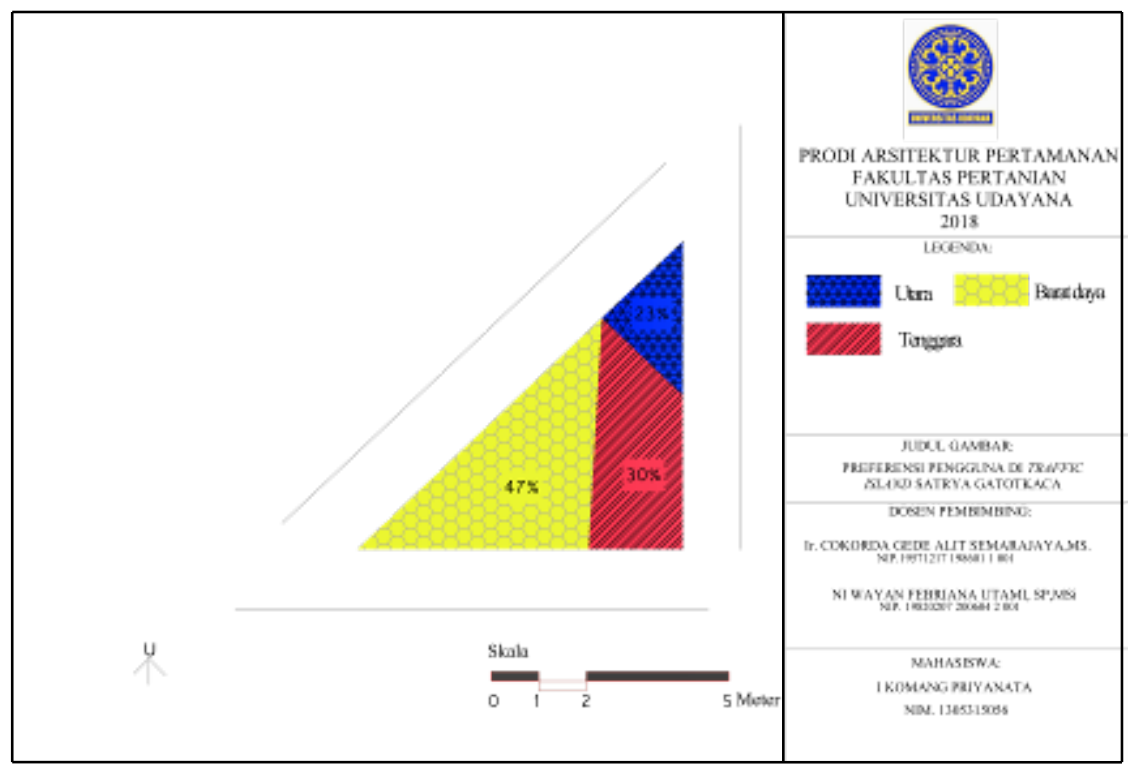

Gambar 5. Blok Plan Preferensi Pengguna di Traffic Island Satrya Gatotkaca

Bagian yang berwarna biru merupakan bagian utara dari TISG, sebanyak 23\% pengguna yang mengunjungi tempat tersebut karena lokasi berada dibelakang patung sehingga tidak cocok untuk dijadikan objek berfoto bagi pengguna. Bagian yang berwarna kuning yaitu pada bagian barat daya taman Satrya Gatotkaca, $47 \%$ pengguna memilih tempat tersebut dengan alasan tempat yang bagus digunakan untuk berkumpul bersama teman-teman, sebagai tempat hiburan, nyaman dan lokasi yang tempat untuk menunggu kesempatan menyeberang. Bagian taman yang berwarna merah yaitu pada bagian selatan taman, sebanyak $30 \%$ pengguna memilih tempat tersebut dengan alasan cocok di jadikan objek foto karena tepat berada pada depan patung kuda, dan dapat melihat kendaraan yang berhenti menunggu lampu merah, namun pada saat sore hari lokasi ini kurang diminati karena masih panas, sihingga lokasi ini ramai dikunjungngi ketika malam hari.

\subsection{Komparasi Traffic Island Ciung Wanara di Gianyar dengan Traffic Island Satrya Gatotkaca di Tuban}

Akses masuk pada TICW terdapat pada bagian timur saja sehingga pengguna yang hendak menyebrang harus mengelilingi TICW untuk mendapatkan tempat untuk menyebrang. Berbeda dengan yang terdapat pada TISG, disana terdapat tiga akses masuk yaitu bagian selatan, barat dan pada bagian timur sehingga pengguna yang hendak menyebrang lebih cepat dalam menentukan tempat untuk menyebrang. Pemilihan vegetasi di TICW dengan TISG sangat berbeda. Vegetasi di TICW lebih banyak menggunakan vegetasi yang berukuran besar, yang dapat menghalangi pandangan pengguna kendaraan sedangkan vegetasi yang digunakan di TISG lebih banyak menggunakan tanaman-tanaman rendah. TISG tidak terdapat pedestrian pada bagian pinggirnya sehingga pengguna yang berjalan dibagian pinggir TISG sangat 
berbahaya karena banyaknya kendaraan yang melintas, berbeda dengan desain di TICW dimana pedestrian mengelilingi TICW sehingga pengguna menjadi aman ketika berjalan dibagian pinggir TICW.

Pada TICW bagian pinggirnya terdapat planter box yang berisi tanaman soka sehingga para pengguna tidak dapat masuk secara sembarangan kedalam TICW. Sedangkan pada bagian pinggir TISG tidak tedapatnya planter box atau tanaman yang mengelilingi, sehingga pengguna dapat masuk kedalam TICW dari sisi manapun. Pemilihan material jalan setapak yang digunakan di TICW adalah batu pilah sehingga konturnya menjadi tidak rata sehingga banyak anak kecil yang sedang bermain menjadi terjatuh berbeda dengan pemilihan material jalan setapak yang terdapat di TISG yaitu dengan paving yang konturnya menjadi rata sehingga aman untuk anak-anak. TICW lebih banyak menempatkan fasilitas rekreasi didalamnya seperti bangku taman, dan terdapat juga sound system yang mengiringi air mancur dengan musik. Sehingga banyak pengguna yang tertarik untuk berkunjung ke TICW tersebut tidak seperti di TISG yang hanya menempatkan fasilitas lampu taman dan tempat sampah didalam TISG.

\section{Rekomendasi}

\subsection{Rekomendasi Hardscape di TICW}

Hasil penelititian yang dilakukan di TICW di Gianyar, menyatakan bahwa traffic island tersebut sudah berubah fungsinya menjadi tempat rekreasi bagi masyarakat. Penambahan rambu-rambu Lalulintas sangat diperlukan pada kedua traffic island ini karena minimnya rambu-rambu Lalulintas yang terdapat pada TICW sehingga pengguna menjadi kurang aman. Pemilihan material jalan setapak yang awalnya batu pilah diganti dengan paving, karena dengan menggunakan batu pilah kontur jalan menjadi tidak rata sehingga membuat pengguna tersandung dapat dilihat pada gambar 6 .

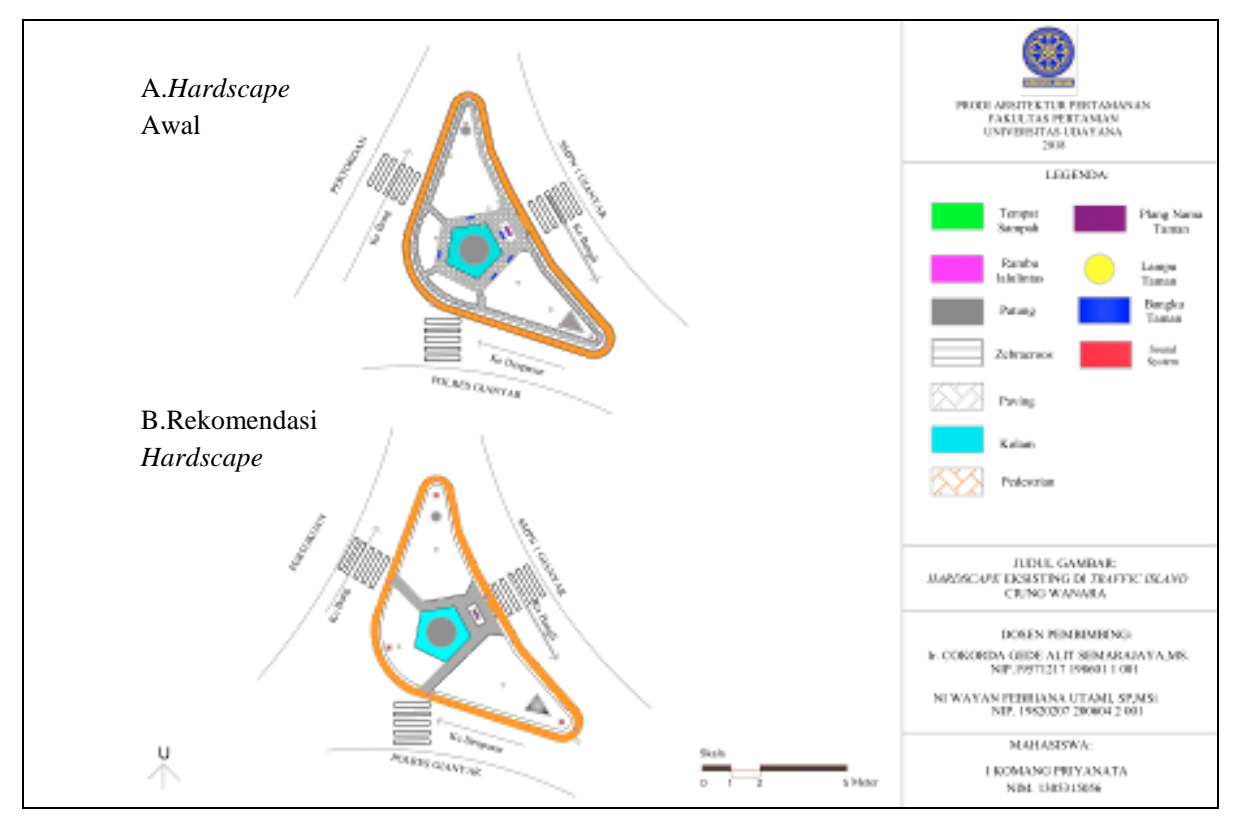

Gambar 6. Rekomendasi Penataan Hardscape Eksisting di TICW

\subsection{Rekomendasi Softscape di TICW}

Pemilihan tanaman yang digunakan di TICW yaitu tanaman yang tidak begitu tinggi agar pengendara dapat melihat kendaraan maupun pengguna yang akan menyeberang pada bagian sebrang. Adapun strata tanaman yang di rekomendasikan pada TICW adalah mulai dari ground cover sampai dengan perdu. Tanaman yang direkomendasikan sebagai peneduh adalah kamboja (plumeria sp), tanaman ini dipilih karena bagian yang rimbun adalah pada bagian atasnya sehingga tidak mengganggu pandangan pengguna kendaraan yang melintas. Jarak tanam untuk tanaman ini juga harus disesuaikan agar tidak terlalu rapat dan tidak mengganggu pandangan pengguna. Dapat dilihat pada gambar 7 . 


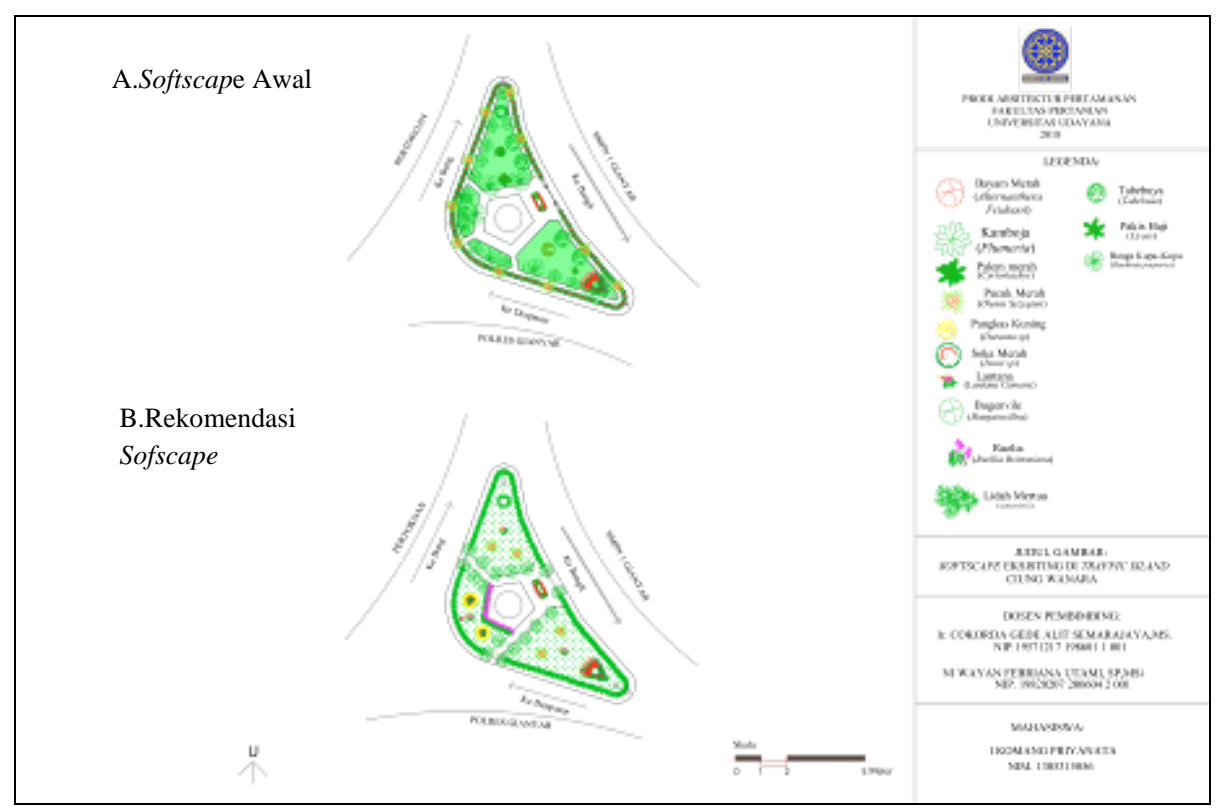

Gambar 7. Rekomendasi Penataan Softscape Eksisting di TICW

\subsection{Rekomendasi Sirkulasi}

Sirkulasi yang direncanakan pada TICW sesuai dengan jalur-jalur yang menghubungkan antara satu ruang dengan ruang yang lainnya. Perubahan sirkulasi dilakukan berdasarkan fungsi tapak yaitu sebagai traffic island, kebutuhan tapak, dan ruang yang ada. Dengan perubahan sirkulasi ini pengguna tidak lagi memutar mengelilingi TICW untuk mendapatkan posisi yang nyaman untuk menyebrang jalan. Dapat dilahat pada gamabar 8 .

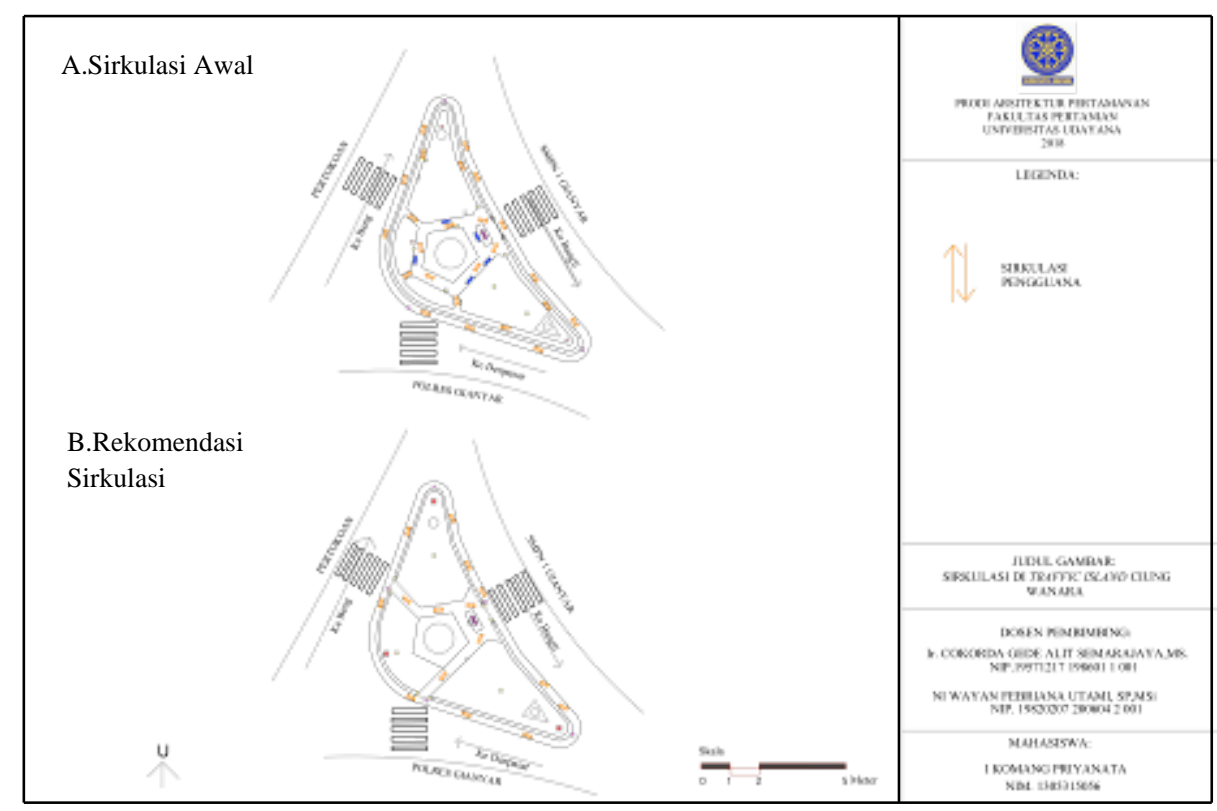

Gambar 8. Sirkulasi Eksisting di TICW

\subsection{Rekomendasi Hardscape di TISG}

Penambahan rambu-rambu Lalu lintas juga dilakukan pada traffic island ini karena minimnya ramburambu Lalu lintas yang terdapat pada TISG. Penambahan zebra cross juga dilakukan pada bagian barat traffic island karena fungsi utama traffic island adalah sebagai lapak tunggu sementara bagi para pengguna 
yang hendak menyeberang sehingga dengan menambkan rambu rambu Lalu lintas dan zebra cross dapat mengembalikan fungsi TISG sebagai Traffic island. Dapat dilihat pada gambar 9.

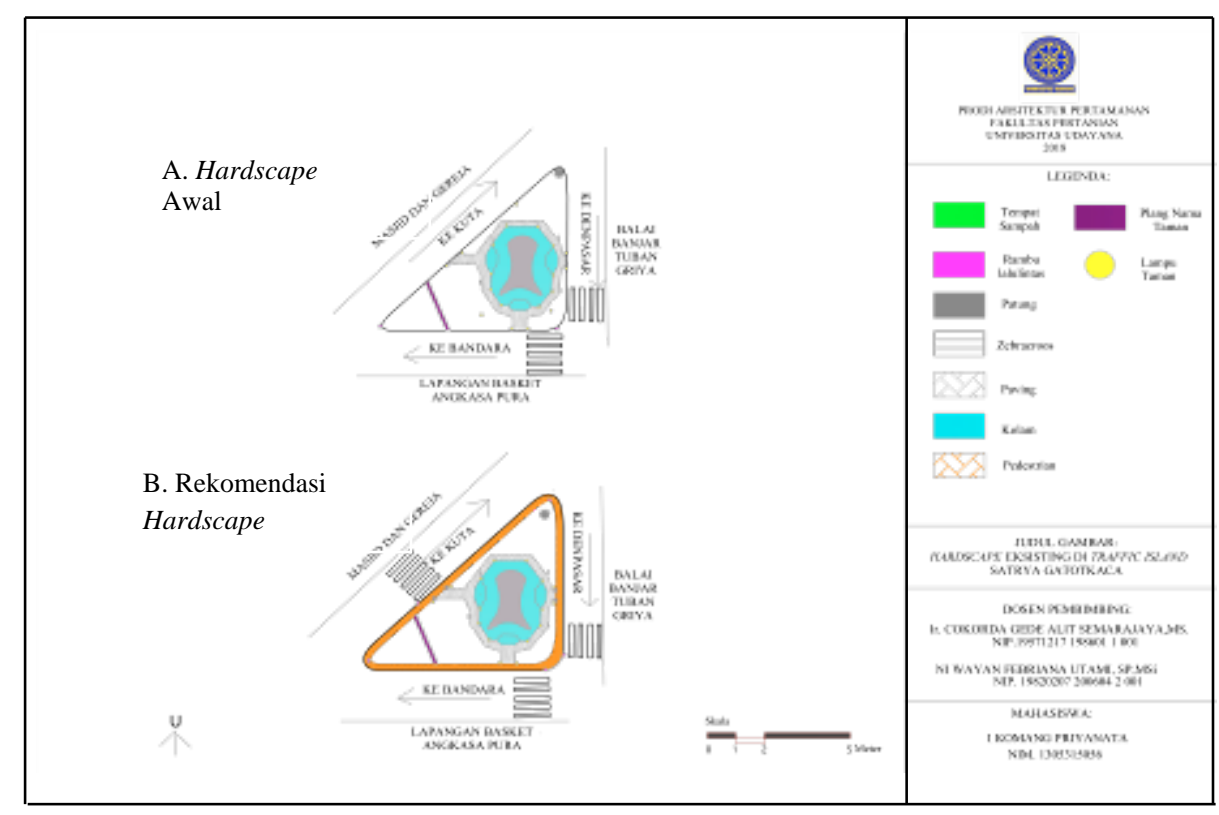

Gambar 9. Rekomendasi Penataan Hardscape Eksisting di TISG

\subsection{Rekomendasi Softscape di TISG}

Pemilihan tanaman yang digunakan di TISG tidak jauh berbeda dengan pemilihan tanaman di TICW yaitu tanaman yang tidak begitu tinggi agar pengendara dapat melihat kendaraan maupun pengguna yang akan menyeberang pada bagian sebrang. Tanaman yang direkomendasikan sebagai peneduh adalah kamboja (plumeria $s p$ ), tanaman ini dipilih karena bagian yang rimbun adalah pada bagian atasnya sehingga tidak mengganggu pandangan pengguna kendaraan yang melintas. Jarak tanam untuk tanaman ini juga harus disesuaikan agar tidak terlalu rapat dan tidak mengganggu pandangan pengguna. Dapat dilihat pada gambar 10.

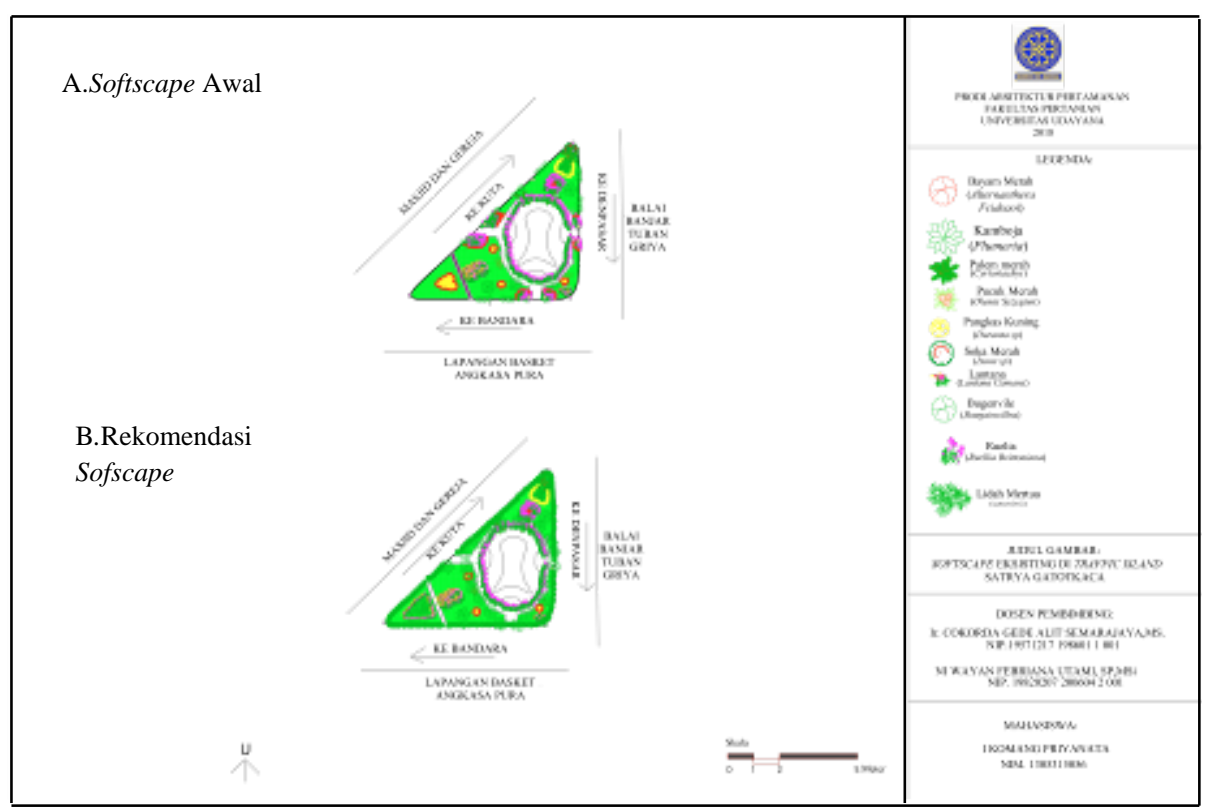

Gambar 10. Rekomendasi Penataan Softscape Eksisting di TISG 


\subsection{Rekomendasi Sirkulasi}

Sirkulasi yang direncanakan pada TISG sesuai dengan jalur-jalur yang menghubungkan antara satu ruang dengan ruang yang lainnya. Perubahan sirkulasi dilakukan berdasarkan fungsi tapak yaitu sebagai traffic island, kebutuhan tapak, dan ruang yang ada. Dapat dilihat pada gambar 11.

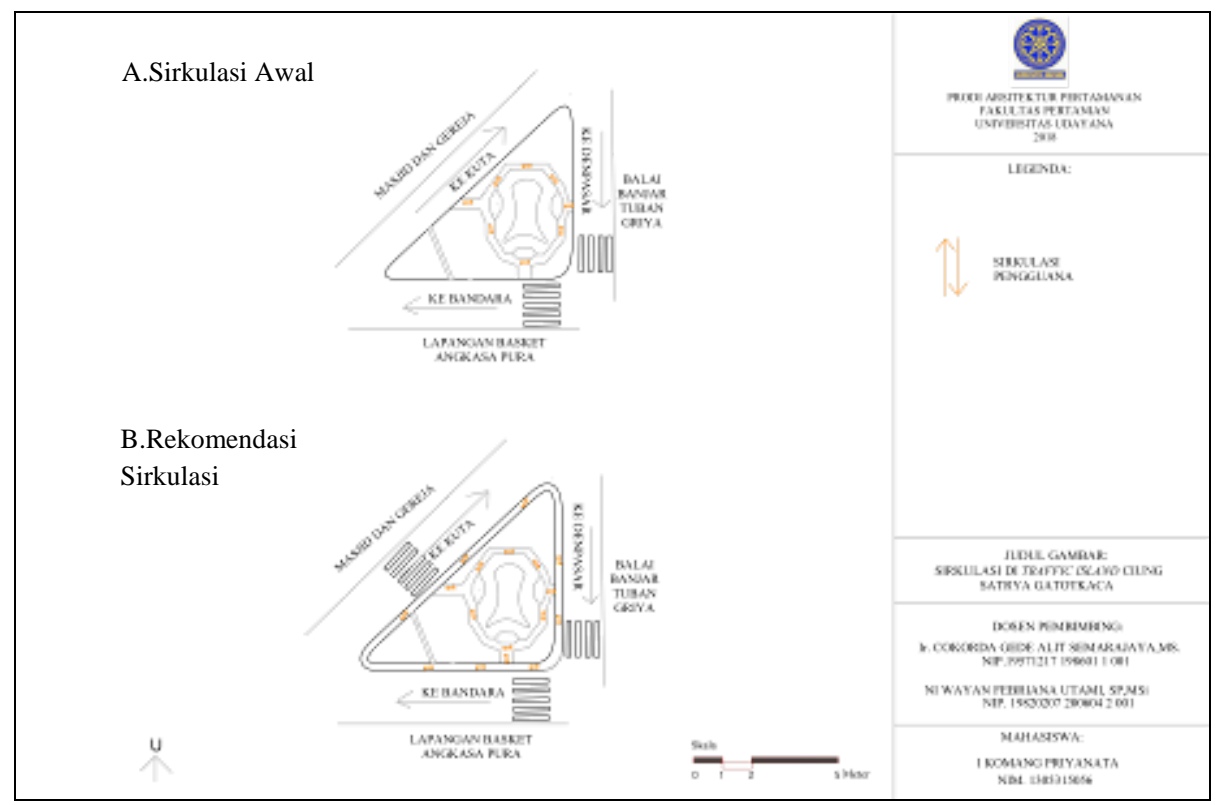

\section{Simpulan dan Saran}

\subsection{Simpulan}

Kondisi eksisting tapak dapat dilihat dari aktifitas pengguna yang datang ke TICW 50\% datang untuk menikmati keindahan taman, karena di TICW terdapat tiga buah patung dan penataan taman yang menarik dan indah. Sedangkan aktifitas pengguna yang datang ke TISG sebanyak 43\% dengan tujuan menyeberang, karena tersedianya akses masuk yang pada bagian barat dan timur yang mampu menunjang fungsi utama tapak. Penenpatan vegetasi di TICW sebanyak $70 \%$ pengguna berpendapat cocok, terutama untuk vegetasi strata pohon $73 \%$ karena vegetasi didalam TICW rimbun sehingga dapat memberikan kesejukan dan kenyamanan bagi pengguna yang berekreasi namun mengganggu penglihatan pengguna lalulintas. Sedangkan di TISG 83\% pengguna berpendapat cocok, terutama pada vegetasi strata pohon $93 \%$ karena pohon yang terdapat pada taman, tidak menghalangi pandangan pengguna kendaraan.

Komparasi antara TICW dengan TISG yaitu pada TICW hanya memiliki satu akses masuk sehingga pengguna yang ingin menyebrang jalan harus memutar untuk menentukan lokasi yang tepat untuk menyebrang. Sedangkan pada TISG terdapat tiga akses masuk sehingga pengguna yang ingin menyebrang jalan lebih mudah dan lebih cepat dalam menentukan lokasi yang tepat untuk menyebrang. Vegetasi yang terdapat pada TICW lebih banyak yang berukuran besar sehingga dapat menghalangi pandangan pengguna kendaraan yang melintas sedangkan vegetasi yang terdapat di TISG lebih banyak menggunakan ground cover sehingga tidak menggangu pandangan pengendara yang melintas.

Rekomendasi yang dapat diberikan pada TICW adalah dengan menambahkan akses masuk dan keluar sehingga pengguna tidak memutar untuk mencari lokasi yang tepat untuk menyebrang. Vegetasi pada TICW diganti dengan ground cover dan perdu agar tidak mengganggu pandangan pengguna kendaraan yang melintas. Sedangkan rekomendasi yang dapat diberikan pada TISG yaitu dengan mengatur ruang penyebrangan agar pengguna lebih nyaman dan aman untuk menyebrang dan memberikan penghalang pada bagian pinggir TISG singga pengguna tidak dapat masuk kedalam TISG dari segala arah.

\subsection{Saran}

Penelitian ini diharapkan dapat dilanjutkan dengan mengacu dari hasil penelitian yang telah didapat pada penelitian ini. Selain itu rekomendasi penelitian dapat menjadi acuan bagi pihak pengelola TICW dan 
Traffic island satrya gatotkaca dalam mengelola kedua Traffic Island. Rencana ruang yang direkomendasikan dalam penelitian ini juga dapat menjadi pertimbangkan bagi pengelola untuk menjadikan kedua traffic island tersebut sesuai dengan fungsinya.

\section{Daftar Pustaka}

Direktur Jenderal Bina Marga. 2012. Panduan Teknis Rekayasa Keselamatan Jalan Direktur Jenderal Bina Marga. Available online at: ndii.co.id/images/dx_publication_file/8619/final-manual-1-ok.pdf. (diakses pada 3 juni 2016).

Sudjana, D. 2001. Metode Statistika. Tarsito. Bandung.

Wulandari. 2016. Cara Pemkot Merawat Taman Kota. Available online at: www.pikiran-rakyat.com. (diakses pada 1 Agustus 2017) 